\title{
Effect of pre-storage seed priming on biochemical changes in Okra seed
}

\author{
Inayat-ur-Rahman ${ }^{1}$, Shamsher Ali $^{2}$, Inayat-ur-Rahman ${ }^{3}$, Muhammad \\ Adnan ${ }^{1 *}$, Hidayat Ullah ${ }^{1}$, Abdul Basir ${ }^{1}$, Muhammad Faisal Anwar \\ Malik $^{1}$, Abdul Sattar Shah ${ }^{1}$, Muhammad Ibrahim ${ }^{1}$ and Muhammd \\ Arshad $^{4}$ \\ 1. Department of Agriculture, the University of Swabi, KPK-Pakistan \\ 2. Department of Soil and Environmental Sciences, the University of Agriculture Peshawar, AMK Campus \\ Mardan-Pakistan \\ 3. Pakistan Council of Scientific and Industrial Research (PCSIR), Peshawar-Pakistan \\ 4. Mountain Agriculture, Research Center (MARC) Gilgit Baltistan-Pakistan \\ *Corresponding author's email: madnanses@gmail.com
}

Citation

Inayat-ur-Rahman, Shamsher Ali, Inayat-ur-Rahman, Muhammad Adnan, Hidayat Ullah, Abdul Basir, Muhammad Faisal Anwar Malik, Abdul Sattar Shah, Muhammad Ibrahim and Muhammd Arshad. Effect of pre-storage seed priming on biochemical changes in Okra seed. Pure and Applied Biology. Vol. 5, Issue 4, pp934-941. http://dx.doi.org/10.19045/bspab.2016.50118

Received: 25/05/2016 Revised: 19/08/2016

Accepted: 25/08/2016

Online First: 28/08/2016

\section{Abstract}

This experiment was conducted to examine the effect of pre-storage seed priming on biochemical changes in okra seed. Two factorial complete randomize design with three repeats was used for this experiment. Seeds were primed with water, polyethylene glycol 8000 (PEG8000) and Mannitol solutions while dry seeds were used as control. After treatment seeds were dried to initial moisture content and then evaluated at zero, 3 and 6 months storage for lipids, aldehydes and electrical conductivity. Results showed that reduction in lipids content and increase in aldehydes and electrical conductivity occurred during storage for each treatment but it was significantly controlled by priming with PEG at $-1.2 \mathrm{Mpa}$ water potential for eighteen hour duration followed by priming with Mannitol at the same water potential and duration as used for PEG priming compared to water treatment and dry seeds.

Keywords: Aldehydes; Electrical conductivity; Storage Okra; Water potential

\section{Introduction}

Seed priming is a pre-sowing seed treatment in which seed is allowed to imbibe enough water to start pre-germinative metabolic processes but insufficient for radicle protrusion because with radicle protrusion seed loses its desiccation tolerance [1]. After hydration, treated seeds are dried back to their initial moisture content. This drying back process is called hydration dehydration and is practiced to minimize deterioration in seed during storage. Priming improves seed germination performance by starting early processes of germination but not cell division [2]. Metabolism that occurs during priming is not enough to cause radicle emergence [3].

In the two types of seed priming, in one type water penetrate freely into seed which is called hydropriming while in other type seed hydration is controlled. If controlled hydration is achieved through the addition of 
solute to water then it is called osmopriming or if a solid matrix is used to provide controlled seed hydration then it is called solid matrix priming [4]. Response of seed to priming is affected by priming duration $[5,6]$, osmotic potential of priming solution [5-7], priming agent [8] and oxygen supply to seed [9].

Seeds deteriorate during storage due to lipids peroxidation [10] and oxidative modification of proteins by reactive oxygen species [11] and lipids per oxidation products e.g. aldehydes [12]. Lipids peroxidation causes disintegration of membrane thereby reducing seed longevity [13] while oxidative modification of protein causes inactivation of antioxidant, hydrolytic and other types of enzymes. Due to the inactivation of antioxidant enzymes, seeds lose their ability to stabilize reactive oxygen species thereby enhancing lipids peroxidation and denaturation of proteins. Inactivation of hydrolytic enzymes such as lipases, proteases and amylases, cause low germination performance of seed because seed germination involve mobilization of storage materials which needs these enzymes. Therefore when these enzymes are inactivated then mobilization of storage materials (lipids, carbohydrates and proteins) will not take place and seed will be unable to germinate [14].

During storage, reactive oxygen species are generated in seed either from molecular oxygen or enzymetically by lipoxygenate enzyme [15] and antioxidant enzymes such as superoxide dismutase, catalase, ascorbate peroxidase and peroxidase decline during storage $[13,16]$ due to which lipids peroxidation increases $[13,17,18]$.

Seed deterioration during storage may be controlled through priming prior to storage $[2,19]$ because priming activates antioxidant enzymes in seed which scavenge reactive oxygen species and lower lipids peroxidation in seed $[20,21]$.
This research work was carried to find out the effect of seed priming and priming agents on instore-biochemical changes in okra seed.

\section{Materials and methods}

Seeds were taken from okra plants at the time of full maturity and were primed with PEG, Mannitol and water at $-1.2,-1.2$ and 0 Mpa water potential respectively while dry seeds were used as control. After priming seeds were rinsed with water and dried back to its initial moisture content at room temperature. After drying seeds were stored at room temperature for six months and were evaluated at zero storage, three months storage and six months storage for lipids, aldehydes and electrical conductivity.

\section{Lipids extraction}

For lipids extraction okra seeds were grinded and $25 \mathrm{~g}$ of the grinded material and petroleum ether as a solvent were added to Soxhlet extractor, after extraction, the extracted material was kept in oven for one hour to evaporate petroleum ether, after that the remaining material was weighed and converted into percentage [22].

\section{Aldehydes determination}

Standard (aldehyde) $10 \mu \mathrm{L}$ with $150 \mathrm{ml}$ boiling distilled water covered with aluminum foil was swirled for45 seconds. After swirling, 5ml gas was collected and injected to GC-MS through syringe manually [23].Ten gram sample with $150 \mathrm{ml}$ boiling distilled water was covered with aluminum foil and swirled for twominutes with gentle heat. After swirling, $5 \mathrm{ml}$ gas was injected manually to GC-MS and data were recorded.

\section{Electrical conductivity}

To determine electrical conductivity of okra seeds, $150 \mathrm{ml}$ distilled water was taken in $250 \mathrm{ml}$ flask and 70 seeds were soaked for 12 hours in it, after 12 hours an electrical conductivity meter was dipped in the flask and electrical conductivity of the seeds was determined in $\mu \mathrm{s} / \mathrm{cm}$. A blank experiment 
i.e. without seeds was also conducted.

\section{Results and discussion Percent lipids}

Analysis of the data revealed that priming agents, storage period and their interaction significantly affected lipids content of the seeds. Storage period and priming agent interaction (Table 1) indicated that for each priming agent significant reduction occurred in lipids content both at three and six month storage period except PEG treated seeds for which reduction at three months storage was insignificant. Maximum reduction was recorded after six months storage for each priming agent It is evident from the data that the effect of storage duration at zero storage was significantly higher in lipids content $(15.69 \%)$ than other storage periods, storing seeds for 180 days reduced it to $13.35 \%$, as a whole it is $15.07 \%$ reduction. However in the first three months storage, reduction in lipids content was only $3.24 \%$. Data in the table relating to priming agents effect on lipid content during storage show that in unprimed seeds lipid content was significantly reduced to $14.17 \%$. On the other hand, priming with PEG helped retaining seed lipids at $15.46 \%$ followed by Mannitol priming which retained lipid content at $14.91 \%$ compared to water priming (14.46\%).

Table 1 represent data that indicate variation in seed lipids content as a function of priming and storage. Overall reduction in lipid content ranges between $6.39 \%$ in seeds primed with PEG to $22.85 \%$ in seeds stored for six months without priming. Seeds primed with PEG have statistically the least reduction (from 15.95 to $14.93 \%$ ) in their lipid content after six months storage. It was followed by those primed with Mannitol where reduction during similar storage period reached (from 15.69 to $13.76 \%$ ), this drop is double as compared to that primed with PEG. Maximum lipids reduction during six month storage was recorded in unprimed seeds which were $15.62 \%$ on zero day and $12.05 \%$ after six months, it is $22.85 \%$ drop and is almost four times greater reduction in lipids contents as compared to seeds primed with PEG. It was followed by hydroprimed seeds which was $18.98 \%$ reduction during six months storage.

Reduction in lipid content of the seeds during storage has been reported by other scientist as well. According to [13, 24 ] lipid reduction in storage may be due to lipid peroxidation, because [8]reported that during storage reactive oxygen species are generated in seed either from molecular oxygen or through enzymetically by lipoxygenate enzyme and according to [15] antioxidant enzymes such as superoxide dismutase, catalase, ascorbate peroxidase and peroxidase which stabilize reactive oxygen species decline during storage due to which lipids peroxidation increases during storage and much reduction occur in lipid content of seed. [8] reported that lipid peroxidation increase leakage from cellular membrane and make it rigid and impermeable due to which loss in seed viability occurs.

Unprimed seeds countered more reduction in lipids during storage as compared to primed seeds, according to $[13,21]$, it may be due to the activation of antioxidant enzymes in primed seeds which scavenge reactive oxygen species and lower lipids peroxidation in seed. [25] have reported that priming with water (hydropriming) is less effective in controlling seed lipid reduction as compared to osmopriming where hydration is controlled, because controlled hydration results in least or no damage to the seed coat compared to uncontrolled hydration. [26] also found that lipid oxidation is high in open oil and in grinded seeds as compared to intact seeds, since hydropriming causes damage to seed coat therefore lipids oxidation will be high in hydroprimed seeds during storage than 
osmoprimed seeds and more reduction in lipids will occur during storage in hydroprimed seeds than osmoprimed seeds. PEG primed seeds were better than Mannitol primed seeds at each storage period with respect to lipid content which may be due to the inert and larger molecular size of PEG which prevent it from penetrating in seed and causing toxicity [8]. The findings of
[27] that priming of seeds before storage decreases loss of viability during storage provide support to the finding of our experiment "that lipids content of the seeds decreases during storage and this decrease may be controlled through priming" because lipids reduction may be correlated to loss of viability.

Table 1. Effect of seed priming and storage duration on lipids (\%) content of okra seed

\begin{tabular}{|l|l|l|l|l|}
\hline \multirow{2}{*}{ Priming agent } & \multicolumn{4}{l|}{ Storage period } \\
\cline { 2 - 5 } & 0 Storage & 3 Months & 6 Months & Mean \\
\hline PEG & $15.80 \mathrm{a}$ & $15.63 \mathrm{a}$ & $14.93 \mathrm{~cd}$ & $15.46 \mathrm{a}$ \\
\hline Mannitol & $15.69 \mathrm{a}$ & $15.28 \mathrm{~b}$ & $13.76 \mathrm{e}$ & $14.91 \mathrm{~b}$ \\
\hline Water & $15.64 \mathrm{a}$ & $15.09 \mathrm{bc}$ & $12.67 \mathrm{f}$ & $14.46 \mathrm{c}$ \\
\hline Unprimed & $15.62 \mathrm{a}$ & $14.85 \mathrm{~d}$ & $12.05 \mathrm{~g}$ & $14.17 \mathrm{~d}$ \\
\hline Mean & $15.69 \mathrm{a}$ & $15.21 \mathrm{~b}$ & $13.35 \mathrm{c}$ & \\
\hline
\end{tabular}

$\operatorname{LSD}_{(0.05)}$ Priming agents $=0.13$,Storage period $=0.11$ and Priming agents $\times$ Storage period $=0.22$

\section{Aldehydes accumulation}

Data in Table 2 indicates that storage duration, priming agents and their interaction have significant effect on aldehydes accumulation in okra seed. it was observed that fresh seeds had no hexanal content but storage for three months caused non-significant enhancement in hexanal for PEG primed seeds, while significant enhancement in aldehydes content occurred for mannitol primed seeds, hydro primed seeds and unprimed seeds, however this enhancement, after three months was insignificant from one another. Storage for six months caused significant increase in aldehydes content for all treatments and all the treatments at this storage period were significantly different from one another in aldehydes content. Lowest aldehydescontent was noted for PEG primed seeds followed by Mannitol primed seeds while highest aldehydes content was noted for unprimed seeds followed by hydro primed seeds. Data relating to storage effect on aldehydes content showed that no aldehydes was found for fresh seeds while the content increased to 1.83 with the passage of three months. After another 3 months (6 months), Aldehyde content enhanced to 23.66 (12 fold enhancement). Aldehydes cause rancidity in oily products and seeds. It also deteriorates the quality and seed ability to emerge. Prolong storage caused high aldehydes content in okra seeds for each treatment however this enhancement was significantly curtailed through priming as compared to unprimed seeds. In priming agents, lowest enhancement for aldehydes was observed for PEG treated seeds, followed by Mannitol and then hydro primed seeds.

Aldehydes usually cause rancidity in oily products and seeds. It also impairs the edible quality and seed potential to germinate. Aldehydes content of okra seeds increased for each treatment with prolong storage but this increase was significantly controlled through priming as compared to unprimed seeds. In the primed seeds, least increase was observed for PEG primed seeds, followed by Mannitol primed seeds and then water primed seeds. 
$[28,29]$ claim that aldehydes accumulates in seed during storage due to lipids peroxidation because it is a product of lipids peroxidation. [13, 18], further explain that lipid peroxidation converts long chain unsaturated fatty acids to short chain compounds e.g. aldehydes, hydrocarbons and alcohols. This conversion damages cellular membrane which disintegrates and results in loss of seed viability. According to [30] aldehydes content in seed is an indication of how much deterioration has taken place in seed during storage. [12] reported that aldehydes denature proteins which cause inactivation of antioxidant and hydrolytic enzymes. [31] had also reported that aldehydes accumulated in seeds and other oily products during storage According to [20] aldehydes accumulation in seed during storage may be controlled through priming. [21] reported that priming activates antioxidant enzymes which stabilize free radicals that results in reduced peroxidation of seed lipids and reduced accumulation of aldehydes in stored seeds because aldehydes are the secondary product of lipids peroxidation.

Osmoprimed seeds significantly controlled aldehydes production in seed during storage than hydroprimed seeds. According to [25] this may be due to controlled hydration in osmopriming due to which seed coat remain intact while in uncontrolled imbibitions rupture occurs in seed coat due to rapid penetration of water into seed. Since seed coat control autooxidation in seed and rupture increases autooxidation in seed thereby enhancing aldehydes production in seed during storage.

Seeds osmoprimed with PEG prior to storage were better in controlling aldehydes production during storage than seeds osmoprimed with Mannitol. According to $[8,32]$ it may be due to smaller molecular size of Mannitol which penetrates in seed and causing toxicity to seed, which might have resulted in high hexanal accumulation in seed. [27, 33] reported that seed priming before storage enhanced seed longevity, this finding is in close conformity with the present finding.

Table 2. Effect of Seed priming and storage period on aldehydes accumulation $\left(\mu \mathrm{g} / \mathrm{Kg}^{-1}\right)$ in okra seeds

\begin{tabular}{|l|l|l|l|l|}
\hline \multirow{2}{*}{ Priming agent } & \multicolumn{4}{|c|}{ Storage period } \\
\cline { 2 - 5 } & 0 Storage & 3 Months & 6 Months & Mean \\
\hline PEG & $0 \mathrm{~g}$ & $0.82 \mathrm{f} \mathrm{g}$ & $13.33 \mathrm{~d}$ & $4.71 \mathrm{~d}$ \\
\hline Mannitol & $0 \mathrm{~g}$ & $1.57 \mathrm{ef}$ & $20.33 \mathrm{c}$ & $7.30 \mathrm{c}$ \\
\hline Water & $0 \mathrm{~g}$ & $2.17 \mathrm{ef}$ & $26.66 \mathrm{~b}$ & $9.61 \mathrm{~b}$ \\
\hline Unprimed & $0 \mathrm{~g}$ & $2.75 \mathrm{e}$ & $34.33 \mathrm{a}$ & $12.36 \mathrm{a}$ \\
\hline Mean & $0 \mathrm{c}$ & $1.83 \mathrm{~b}$ & $23.66 \mathrm{a}$ & \\
\hline
\end{tabular}

$\operatorname{LSD}_{(0.05)}$ Priming agents $=0.86$, Storage period $=0.74$ and Priming agents $\times$ Storage period $=1.49$

Electrical conductivity

Analysis of the data revealed that there is significant effect of priming agent, storage period and interaction of both on electrical conductivity of okra seed.

From the data in Table 3 it is evident that electrical conductivity of fresh seeds is low which is an indication of firm and intact membrane, with aging membrane disintegrate which increases electrical conductivity of seeds. PEG treated seeds have $97.88 \mu \mathrm{s} / \mathrm{cm}$ electrical conductivity which is significantly lower than unprimed seeds $(140.33 \mu \mathrm{s} / \mathrm{cm})$ and other treatments. Mannitol also played an important role in retaining electrical conductivity at the low 
level $(111.22 \mu \mathrm{s} / \mathrm{cm})$ compared to priming seeds with water $(122.25 \mu \mathrm{s} / \mathrm{cm})$ and unprimed seeds $(140.33 \mu \mathrm{s} / \mathrm{cm})$. Mannitol however could not perform as PEG. Long storage (aging) also played a crucial role in seed degradation. Six months storage enhanced electrical conductivity from $72.41 \mu \mathrm{s} / \mathrm{cm}$ to $182.16 \mu \mathrm{s} / \mathrm{cm}$ which indicates membrane degradation and resultant seed deterioration. Three months storage, however, seems less harmful than six months storage. Data in the table indicate that PEG treated seeds stored for three months are as healthy as freshly harvested seeds $\quad(60.66 \mu \mathrm{s} / \mathrm{cm}$ versus $72.66 \mu \mathrm{s} / \mathrm{cm}$ difference statistically non-significant). On the contrary unprimed seeds and seeds treated with water and Mannitol stored for three months showed an enhanced electrical conductivity $(138.33 \mu \mathrm{s} / \mathrm{cm}, 97 \mu \mathrm{s} / \mathrm{cm}$ and $89.66 \mu \mathrm{s} / \mathrm{cm}$ respectively) compared to $72.66 \mu \mathrm{s} / \mathrm{cm}$ in seeds treated with PEG.

Electrical conductivity significantly increased for each priming agent and unprimed seeds after six months storage, but it was statistically lower for osmoprimed seeds (PEG and Mannitol primed seeds) as compared to water treated seeds and unprimed seeds (Dry seeds).According to [8] reactive oxygen species increases during storage while $[13,16]$ reported that antioxidant enzymes decline during storage Table 3. Effect of seed priming and storage period on electrical conductivity $\left(\mu \mathrm{s} / \mathrm{cm}^{-1}\right)$ of okra seed

\begin{tabular}{|l|l|l|l|l|}
\hline \multirow{2}{*}{ Priming agent } & \multicolumn{4}{l}{ Storage period } \\
\cline { 2 - 5 } & 0 Storage & 3 Months & 6 Months & Mean \\
\hline PEG & $65 \mathrm{~g}$ & $77 \mathrm{f}$ & $150 \mathrm{c}$ & $97.33 \mathrm{c}$ \\
\hline Mannitol & $67 \mathrm{~g}$ & $83 \mathrm{e}$ & $171 \mathrm{~b}$ & $107 \mathrm{~b}$ \\
\hline Water & $68 \mathrm{~g}$ & $94 \mathrm{~d}$ & $193 \mathrm{a}$ & $118 \mathrm{a}$ \\
\hline Unprimed & $68 \mathrm{~g}$ & $96 \mathrm{~d}$ & $196 \mathrm{a}$ & $120 \mathrm{a}$ \\
\hline Mean & $67 \mathrm{c}$ & $87.50 \mathrm{~b}$ & $177.5 \mathrm{a}$ & \\
\hline
\end{tabular}

$\operatorname{LSD}_{(0.05)}$ Priming agents $=2.22$, Storage period $=1.39$ and Priming agents $\times$ Storage period $=3.85$

Conclusion and recommendations

Priming proved to be effective in lowering seed damage during storage as compared to due to which lipids peroxidation enhances during storage, according to [10] lipids peroxidation causes membrane disintegration and leakage from cells, this membrane disintegration and leakage results in loss of seed viability and enhances electrical conductivity of seeds.

Water treated seeds showed more electrical conductivity during storage than osmoprimed seeds i.e. seeds treated with PEG and Mannitol solutions. According to $[25,29]$ in hydropriming uncontrolled imbibition causes damage to seed coat and cellular membrane, due to which leakage increases from seed, this damage also exposes seed lipids to atmospheric oxygen thereby increaseing lipids peroxidation which causes disintegration of cellular membrane and enhances leakage from seed thereby increasing electrical conductivity of the seeds.

Osmoprimed seeds significantly controlled increase in electrical conductivity during storage as compared to unprimed seeds. [20, 21] have reported that priming activates antioxidant enzymes which reduces peroxidation of lipids in seed by stabilizing reactive oxygen species generated in seed during storage thereby results in low damage to membrane and low solute leakage from seed cells due to which increase in electrical conductivity comes under control [20, 21]. 
storage for all priming agents. In priming agents PEG 8000 was more effective followed by Mannitol and hydro-priming respectively. Priming with PEG 8000 prior to storage was is the best one for controlling seed damage during storage. Thus it is suggested that okra seeds may be primed with PEG 8000 for 18 hours to minimize seed damage before storage.

\section{Authors' contributions}

Conceived and designed the experiments: IU Rahman, Performed the experiments: IU Rahman, S Ali, IU Rahman \& M Adnan, Analyzed the data: IU Rahman, S Ali, IU Rahman \& M Adnan, Contributed reagents/ materials/ analysis tools: IU Rahman, S Ali, IU Rahman \& M Adnan, M Ibrahim, AS Shah, A Basir, MFA Malik \& M Arshad, Wrote the paper: IU Rahman, S Ali, IU Rahman \& M Adnan.

\section{References}

1. Heydecker W, Higgins $\mathrm{J} \&$ Gulliver RL (1973). Accelerated germination by osmotic seed treatment. Nature 42-44.

2. Georghiou K, Thanos CA \& Passam HC (1987). Osmoconditioning as a means of counteracting the ageing of pepper seeds during high-temperature storage. Annals of Botany 60(3): 279-285.

3. Sung JM (1996). Lipid peroxidation and peroxide-scavenging in soybean seeds during aging. Physiologia Plantarum 97(1): 85-89.

4. Dursun A \& Ekinci M (2010). Effects of different priming treatments and priming durations on germination percentage of parsley (Petroselinum crispum L.) seeds. Agricultural Sciences 1(01): 17.

5. Neamatollahi E, Bannayan M, Darban AS \& Ghanbari A (2009). Hydropriming and osmoprimingeffects on cumin (Cuminum cyminum L.) seeds germination. World Academy of Science, Engineering and Technology 57: 526-529.

6. Sadeghi H, Khazaei F, Yari L \& Sheidaei S (2011). Effect of seed osmopriming on seed germination behavior and vigor of soybean (Glycine max L.). ARPN Journal of Agricultural and Biological Science
6(1): 39-43.

7. Moradi A \&Younesi O (2009). Effects of osmo-and hydro-priming on seed parameters of grain sorghum (Sorghum bicolor L.). Australian Journal of Basic and Applied Sciences 3(3): 1696-1700.

8. Moosavi A, Tavakkol, Afshari R, SharifZadeh F \& Aynehband A (2009). Effect of seed priming on germination characteristics, polyphenoloxidase, and peroxidase activities of four amaranth cultivars. J Food Agric Environ 7(3-4): 353-358.

9. Basra S, Afzal I, Rashid RA \& Farooq M (2005). Pre-sowing seed treatments to improve germination and seedling growth in wheat (Triticum aestivum L.). Biology series Search Pad 17(1): 155-164.

10. Bujalski W, Nienow AW, Maude RB \& Gray D (1993). Priming responses of leek (Allium porrum L.) seeds to different dissolved oxygen levels in the osmoticum. Annals of Applied Biology 122(3): 569577.

11. Sung JM \& Jeng TL (1994). Lipid peroxidation and peroxide-scavenging enzymes associated with accelerated aging of peanut seed. Physiologia Plantarum 91(1): 51-55.

12. Yari L, Aghaalikhani $M$ \& Khazaei $F$ (2010). Effect of Seed priming duration and temperature on seed germination behavior of bread wheat (Triticum aestivum L.). ARPN Journal of Agricultural and Biological Science 5(1): 5-8.

13. Akimoto $\mathrm{T}$, Cho $\mathrm{S}$, Yoshida $\mathrm{H}$, Furuta $\mathrm{H}$ \& Esashi Y (2004). Involvement of acetaldehyde in seed deterioration of some recalcitrant woody species through the acceleration of aerobic respiration. Plant and cell physiology 45(2): 201-210.

14. Sung JM \& Chiu CC (1995). Lipid peroxidation and peroxide-scavenging enzymes of naturally aged soybean seed. Plant Science 110(1): 45-52.

15. Job C, Rajjou L, Lovigny Y, Belghazi M \& Job D (2005). Patterns of protein oxidation in Arabidopsis seeds and during germination. Plant Physiology 138(2): 790-802. 
16. Pukacka S \& Ratajczak E (2005). Production and scavenging of reactive oxygen species in Fagussylvatica seeds during storage at varied temperature and humidity. Journal of plant physiology 162(8), 873-885.

17. Goel A \& Sheoran IS (2003). Lipid peroxidation and peroxide-scavenging enzymes in cotton seeds under natural ageing. Biologia Plantarum, 46(3): 429434.

18. Harman GE \& Mattick LR (1976). Association of lipid oxidation with seed ageing and death. 323-324.

19. Boonsiri K, Ketsa S \& Van Doorn WG (2007). Seed browning of hot peppers during low temperature storage. Postharvest Biology and Technology 45(3): 358-365.

20. Probert RJ, Bogh SV, Smith AJ \& Wechsberg GE (1991). The effects of priming on seed longevity in Ranunculus sceleratus L. Seed Science Research 1(04): 243-249.

21. Braccini ADLE, Reis MS, Moreira MA, Sediyama CS \& Scapim CA (2000). Biochemical changes associated to soybean seeds osmoconditioning during storage. Pesquisa Agropecuária Brasileira 35(2): 433-447.

22. Khan AA, Tao K, Knypl JS, Borkowska B \& Powell LE (1977). Osmotic conditioning of seeds: physiological and biochemical changes. In Symposium on Seed Problems in Horticulture 83: 267278.

23. Pastorelli S, Valzacchi S, Rodriguez A \& Simoneau C (2006). Solid-phase micro extraction method for the determination of hexanal in hazelnuts as an indicator of the interaction of active packaging materials with food aroma compounds. Food additives and contaminants 23(11): 12361241.

24. Priestley DA \& Leopold AC (1983). Lipid changes during natural aging of soybean seeds. Physiologia Plantarum 59(3): 467470.

25. Sung JM (1996). Lipid peroxidation and peroxide-scavenging in soybean seeds during aging. Physiologia Plantarum 97(1): 85-89.

26. Yasseen Y, Barringer SA, Splittstoesser WE \& Costanza S (1994). The role of seed coats in seed viability. The Botanical Review 60(4): 426-439.

27. Priestley DA, Werner BG \& Leopold AC (1985). The susceptibility of soybean seed lipids to artificially-enhanced atmospheric oxidation. Journal of Experimental Botany 36(10): 1653-1659.

28. Basra SM, Ullah Ehsan, Warraich EA, Cheema MA \& Afzal I (2003). Effect of storage on growth and yield of primed canola (Brassica napus) seeds. International journal of agriculture and biology 5(2): 117-120.

29. Ross CF \& Smith DM (2006). Use of volatiles as indicators of lipid oxidation in muscle foods. Comprehensive Reviews in Food Science and Food Safety 5(1): 1825.

30. Sedaghat N \& HabibiNajafi MB (2010). Influence of different packaging systems on stability of raw dried pistachio nuts at various conditions. American-Eurasian Journal of Agricultural \& Environmental Science 8: 576-581.

31. Zhang M, Maeda Y, Furihata Y, Nakamaru $Y$ \& Esashi Y (1994). A mechanism of seed deterioration in relation to the volatile compounds evolved by dry seeds themselves. Seed Science Research 4(01): 49-56.

32. Rahman UI, Ali S, Rahman IU, Adnan M, Ibrahim M, Saleem N \& Irshad M 2016. Effect of seed priming on growth parameters of Okra (Abelmoschus esculentus L.). Pure and Applied Biology 5(1): 165-171.

33. Nascimento WM (2003). Muskmelon seed germination and seedling development in response to seed priming. Scientia Agricola 60(1): 71-75.

34. Dearman J, Brocklehurst PA \& Drew RLK (1986). Effects of osmotic priming and ageing on onion seed germination. Annals of Applied Biology 108(3): 639-648. 